\title{
Heat Roadmap Europe: Large-Scale Electric Heat Pumps in District Heating Systems
}

\author{
Andrei David ${ }^{1, *}$, Brian Vad Mathiesen ${ }^{1}$, Helge Averfalk ${ }^{2}$, Sven Werner ${ }^{2}$ and Henrik Lund ${ }^{3}$ \\ 1 Department of Planning, Aalborg University, AC Meyers Vænge 15, 2450 Copenhagen, Denmark; \\ bvm@plan.aau.dk \\ 2 School of Business, Engineering and Science, Halmstad University, PO BOX 823, SE 30118 Halmstad, \\ Sweden; helge.averfalk@hh.se (H.A.); sven.werner@hh.se (S.W.) \\ 3 Department of Planning, Aalborg University, Rendsburggade 14, 9000 Aalborg, Denmark; lund@plan.aau.dk \\ * Correspondence: andrei@plan.aau.dk; Tel.: +45-2477-7368
}

Academic Editor: Kamel Hooman

Received: 13 March 2017; Accepted: 18 April 2017; Published: 22 April 2017

\begin{abstract}
The Heat Roadmap Europe (HRE) studies estimated a potential increase of the district heating $(\mathrm{DH})$ share to $50 \%$ of the entire heat demand by 2050 , with approximately $25-30 \%$ of it being supplied using large-scale electric heat pumps. This study builds on this potential and aims to document that such developments can begin now with technologies currently available. We present a database and the status of the technology and its ability of expansion to other European locations by reviewing experiences aimed at further research or application in the heating industry. This is based on a survey of the existing capacity of electric large-scale heat pumps with more than $1 \mathrm{MW}$ thermal output, operating in European DH systems. The survey is the first database of its kind containing the technical characteristics of these heat pumps, and provides the basis for the analysis of this paper. By quantifying the heat sources, refrigerants, efficiency and types of operation of 149 units with $1580 \mathrm{MW}$ of thermal output, the study further uses this data to analyze if the deployment of this technology on a large-scale is possible in other locations in Europe. It finally demonstrates that the technical level of the existing heat pumps is mature enough to make them suitable for replication in other locations in Europe.
\end{abstract}

Keywords: large-scale electric heat pumps; district heating; waste heat; sewage water; natural refrigerants; energy system flexibility

\section{Introduction}

It is generally agreed that the quantity of carbon emissions released in the atmosphere as a result of human activities has reached alarming levels. In December 2015, at the 21st Conference of Parties summit in Paris, a historic agreement was reached regarding climate changes. It was the first pact of its kind to cut the carbon emissions and to limit the rising global temperatures to "well below $2{ }^{\circ} \mathrm{C}$, aiming for $1.5^{\circ} \mathrm{C}^{\prime \prime}$ by 2100 [1]. To achieve this reduction, the EU has set itself a long-term goal to reduce greenhouse gas (GHG) emissions by $80-95 \%$ before the year 2050, as compared to the 1990 levels [2]. Currently on a European level, energy and transport account for more than $75 \%$ of the current $\mathrm{CO}_{2}$ emissions [3], and for these two uses the European Union (EU) imports 53\% of the fossil fuel energy it consumes at a price of over $€ 1$ billion per day [4]. The heating and cooling sector is estimated to use half of the total energy consumed in Europe [5]. At the same time, potential wasted heat from industry and electricity production is on the same order of magnitude as the total heating demand of all buildings in Europe, indicating that there is a possibility to reduce both the imported and consumed energy, to decarbonize the energy sector, and increase the security of supply. 
The heating sector has a decisive role in achieving these goals, and to mitigate its negative impact, energy efficiency improvement measures are required on both the supply and demand side, combined with the inclusion of more renewable energy sources (RES). Much attention was given to the demand side, by retrofitting the building stock, but lately the type of heat supply has received more attention [5]. The synergy between these demand side energy savings and new supply options was analyzed in the Heat Roadmap Europe (HRE) studies [6,7]. The first study, which covered the EU27 countries, focused on increasing DH levels to cover approximately $50 \%$ of the total heat demand. The results indicated that large-scale electric heat pumps and DH systems become increasingly important on a European level. Therefore, the second study, which investigated the potential for a combined retrofitting and district heating strategy, quantified and estimated the large-scale electric heat pumps needed to an aggregated capacity of approximately $40 \mathrm{GW}$ of thermal output, and supply $25-30 \%$ of the total DH production by 2050. DH production for 2050 is calculated to be $1571 \mathrm{TWh} /$ year including $17 \%$ heat losses. The large-scale heat pumps are estimated to produce $520 \mathrm{TWh} /$ year with a coefficient of performance (COP) of 3. Such an increase enables a much larger utilization of alternative sources of heat, from RES to waste heat [7].

Waste heat can come mainly from various exothermic activities. Some of this heat has the desired temperature levels for direct use in the $\mathrm{DH}$ systems, such as the heat produced from thermal power generation. When the temperature levels are not high enough, add-on solutions are required in the shape of large-scale heat pumps, which move the heat from a low-temperature input (the heat source) to a high temperature output (the DH system) through a closed compression process. The advantage of using this technology is its efficiency (e.g., compared to electric boilers) and its ability for using inexpensive sources of heat to balance the thermal and electricity grids [8].

Since the potential to expand the capacities of these heat pumps exists, there seems to be a lack of understanding on the role of this technology by both the heat pump industry and utility companies. This is very concerning, as electric large-scale heat pumps were documented to be a critical part of an integrated Smart Energy System [9]. Such a Smart Energy System enables the flexible and efficient integration of large amounts of fluctuating and intermittent electricity from wind turbines and photovoltaics by interconnecting the electrical, thermal and gas grids. The gas grids and liquid fuels allow for long-term storage, whilst heat pumps, DH and thermal storage allow for the short-term storage [10].

The importance of large-scale electric heat pumps in DH systems has been already analyzed from multiple perspectives. So far, the studies related to this technology have focused on their operational integration with other technologies [11-16], the role in the future Smart Energy Systems [9,17], the availability of heat sources [18], the role in limiting the use of biomass [19] and economic aspects of integrating them on a local or national level [20-22]. HRE studies investigated the role of DH on a European scale, assigning large-scale electric heat pumps with a critical position in the future energy grids [6,7], whilst another study looked into the history and role of large-scale heat pumps in Sweden [23]. None of the studies inquired as to the existing, state-of-the-art technological level of these heat pumps, and if they are ready to assume their role in the future energy systems, namely to integrate the intermittent electricity sources.

Thus, an interest in having an overview of the status of the large-scale electric heat pumps in DH systems triggered the development of this study, which aims to be a first study of the majority of such heat pumps operating in DH systems in the EU28, Norway and Switzerland. The heat pumps outside Europe are not taken into consideration, as the aim of this study is to quantify the status of the technology in the context of the HRE findings, which gives large-scale electric heat pumps a critical role in their proposed future energy scenarios. The scope of this paper is to analyze the existing electricity-driven units with a thermal capacity output equal or greater to $1 \mathrm{MW}$. Absorption heat pumps, as these do not have the capacity to integrate the intermittent RES and thus balance the electric and thermal grids. 
The study quantifies their most relevant technical characteristics to inquire if the technology used nowadays is mature enough to be deployed on a larger scale across Europe to integrate the increasing amounts of intermittent electricity supplied through renewable electricity sources. The intent of this study is to raise awareness and facilitate the access of the stakeholders to more information for a technology for which the knowledge is generally limited.

\section{Materials and Methods}

The units (available in Supplementary Materials), are grouped per country, heating plant and in the decreasing order of their age. The rest of the data includes information on the heat sources, refrigerants used, capacities, COP, input and output temperatures and possibility for providing cooling. The COP and the heat source and heat supply temperatures of the heat pumps in the survey represent average values. The operating hours are available only for a limited number of heat pumps in the survey, and are not included in the survey. For Sweden, the average operating hours for almost all heat pumps are based on the capacity factor and its aggregated values.

The structure of the analysis focuses on the findings of the survey: capacities and market development, heat sources, refrigerants, COP, output temperatures and types of operation, and then considers the possible deployment based on the main findings.

Data collection was performed between September 2015 and February 2017, mainly through online research from heat pump manufacturers, utility companies, newspapers and fact sheets of energy companies, presentations and databases of national DH associations. However, valuable information was also provided through email and phone correspondence with project, utility, association and manufacturer representatives and in interviews with experts. Follow-ups were made using the phone for personal communication with these representatives. The references for this data are presented in the Supplementary Materials. Most of the data for the heat pumps in Sweden have been gathered from a national heat pump survey on large-scale electric heat pumps in DH systems [23].

Therefore, given the different sources and ways of gathering information for this survey, it is likely that some of the data is biased, or could not represent the exact situation on site. Some of the parameters of the heat pumps are based on information which is not always accurate, as various data collection channels were used. Some of the heat pumps, functional at the moment of the data collection, may not be functional at the date of the publication of this study. The authors have tried to the best of their ability to avoid such biases, by conducting expert interviews and having a broad base of empirical data and sources. All the gathered data is published with references so others can improve and continue such efforts. The objective is to provide data for further research, industry, students and others with interest in the field.

\section{Findings of the Survey}

\subsection{Overall Capacities and Market Development}

The data gathered in the Supplementary Materials contains the technical characteristics of large-scale electric heat pumps in DH systems in 11 countries, whilst in the rest of the countries, within the scope of this survey, such large-scale heat pumps were not identified. The survey found 149 units, operating at almost 80 locations across 11 European countries, with an aggregated thermal output capacity of approximately $1580 \mathrm{MW}$. The establishment year of the heat pumps in the survey is known for 143 of the total number of units and it is detailed in Table 1. The table also accounts for the units added later on to existing heat pump plants.

Numerous heat pumps were installed mainly in Sweden in the 1980s, and this was caused, at the time, by a temporary surplus of electricity produced by newly-built nuclear power plants. Given the limited export capacities, the excess electricity had to be used within the country, so a legal framework was created to support an increase of electricity demand, through the installation of individual and large-scale electric boilers and even grant the installation of individual and large-scale heat pumps [23]. 
At the date of the completion of this survey, approximately $1000 \mathrm{MW}$ of the large-scale heat pumps built in Sweden the 1980s were still operational.

Table 1. Overall capacities, number of units and average capacities for the heat pumps where the establishment year is known.

\begin{tabular}{cccc}
\hline Year & Capacity (MW) & Number of Units & Average Capacity (MW) \\
\hline $1981-1985$ & 490 & 37 & 13 \\
$1986-1990$ & 533 & 28 & 19 \\
$1991-1995$ & 35 & 3 & 12 \\
$1996-2000$ & 157 & 10 & 16 \\
$2001-2005$ & 59 & 8 & 7 \\
$2006-2010$ & 173 & 20 & 9 \\
$2010-2016$ & 121 & 37 & 3 \\
Total & 1568 & 143 & 11 \\
\hline
\end{tabular}

The capacities and units installed in the 1990s are considerably lower than in the previous period, and this trend continues through the beginning of the next decade, when very few new heat pumps were built. However, starting with the middle of the last decade, more projects were completed, and this trend spread later to the rest of the countries in the survey, except Sweden, where many heat pumps were decommissioned between 1990 and 2010. It is to be noted that Sweden had 120 units and over $1500 \mathrm{MW}$ of heat pump capacity installed at the early beginning of the 1990s, but a part of this capacity was decommissioned, aggregating 47 units with over $300 \mathrm{MW}$. These were mainly smaller units (below $10 \mathrm{MW}$ ), leaving the larger ones still functional [23]. The main reason for the reduction in the number of heat pumps was that the supply of electricity levelled up with the demand, so the lack of surplus electricity made large-scale heat pumps a less viable solution [8]. The reduction was also related to a higher competition from waste and biomass combined heat and power (CHP), due to market price changes [23], and possibly because of the unreasonable costs for smaller heat pumps to be converted from the high ozone-depleting potential (ODP) refrigerants to environmentally friendlier ones [24].

Table 1 also demonstrates that between 2010 and 2016, more units were installed compared with the previous decade, but the size of these units is smaller. The historical average size of the units in this survey shows a gradual decrease in capacities, from approximately 16 MW for the period 1980-2000, to approximately $5 \mathrm{MW}$ for the period 2001-2016. This change in the size of heat pumps has several causes, and is generally related to the type of refrigerant used (further discussed in Section 4.2), but also to the lack of surplus electricity to be integrated by the heat pumps and the competition from other types of heat supply.

In Figure 1, two observations can be made. Firstly, the heat pumps in Sweden are old, and it is unclear how many years these respective units will continue to function, especially when some of the units will have to implement a refrigerant replacement. A second observation is that in the rest of the countries, new investments for large-scale heat pumps were made, and many projects were commissioned in or after 2006, which was chosen as a border year between the new and older generation of heat pumps. Most of the new projects that were commissioned after 2006, are in more countries such as Denmark, Finland, France and Italy. 


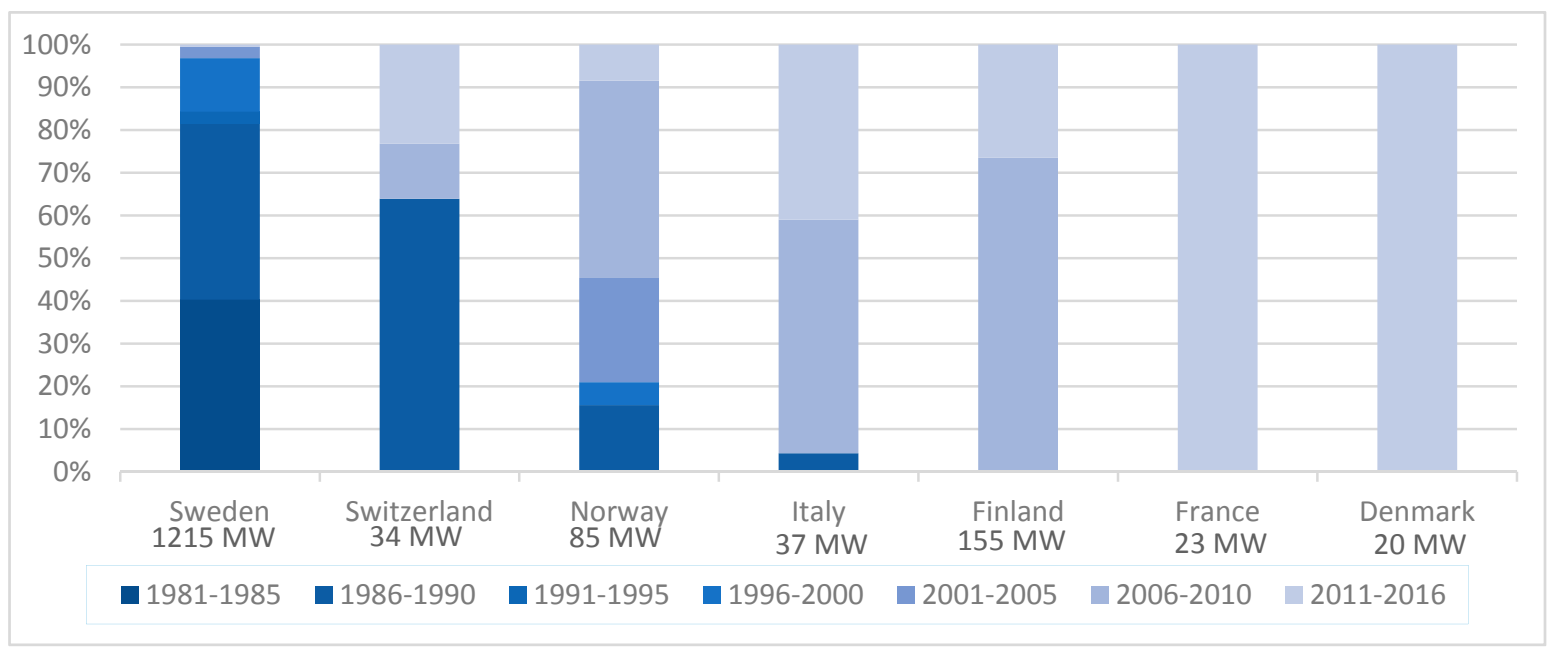

Figure 1. Establishment years and capacities of heat pumps in seven countries with the greatest capacities installed and currently operating.

\subsection{Heat Sources}

There are seven types of heat sources used by the large-scale electric heat pumps in the survey. There is no differentiation in terms of types of heat sources used by the old and new heat pumps. These types of heat sources are detailed in the sections bellow and in Table 2.

1. Sewage water-The most common type of heat source found in the survey, with 54 examples found in Norway, Sweden, Finland and Switzerland. It has been used since 1981. The total installed capacity of the heat pumps using this type of heat source is $891 \mathrm{MW}$, representing $56 \%$ of the total installed capacity, with an average of $17 \mathrm{MW}$ per unit and with a temperature range between 10 and $20^{\circ} \mathrm{C}$. The sewage water is generally treated before being used as heat source, except for some heat pumps in Norway.

2. Ambient water-In the survey, it is represented by the sea, lake and river water and has 34 units with $390 \mathrm{MW}$ of capacity installed. This represents $24 \%$ of the total capacity installed, with an average of $11 \mathrm{MW}$ per unit, and a temperature range for the heat source of 2 to $15^{\circ} \mathrm{C}$.

3. Industrial waste heat-This type of heat source is produced by various industrial processes, and 28 units use it, with a total capacity of $129 \mathrm{MW}$. This represents $8 \%$ of the total capacity installed, with an average capacity for each heat pump of $5 \mathrm{MW}$ and with a temperature range of the heat source between 12 and $46{ }^{\circ} \mathrm{C}$.

4. Geothermal water-This type of heat source is found with 19 units, and a total capacity of $97 \mathrm{MW}$. These heat pumps represent $4 \%$ of the total capacity installed and have an average capacity per unit of $5 \mathrm{MW}$, but with a very wide temperature range for the heat source, of between 9 and $55{ }^{\circ} \mathrm{C}$.

5. Flue gas-The seven units in this survey have a total capacity of $40 \mathrm{MW}$. The average capacity per unit is $6 \mathrm{MW}$, and a temperature range at the heat source between 34 and $60{ }^{\circ} \mathrm{C}$.

6. District cooling-This is used as a heat source by the heat pumps connected to the return pipe of the district cooling network. There are four units built in Sweden, Finland and Denmark, with a total capacity of $30 \mathrm{MW}$ using only this type of heat source, and another four units use district cooling as a secondary heat source, but these were included in the sewage water section. This type of heat source represents the lowest temperature ranges in the survey, between 0 and $9{ }^{\circ} \mathrm{C}$, and the heat pump operating in Høje Taastrup (Denmark) has the lowest temperature heat source in the survey, of $0{ }^{\circ} \mathrm{C}$. 
7. Solar heat storage-All the heat pumps using this type of solar heat source are located in Denmark. These are three units and all have a capacity of $4 \mathrm{MW}$, with an average capacity between 1 and 1.5 MW. The temperature ranges for the heat sources are between 10 and $35^{\circ} \mathrm{C}$.

Table 2. Heat sources for the heat pumps in the survey and some of their most important features.

\begin{tabular}{cccccc}
\hline Type of Heat Source & $\begin{array}{c}\text { Capacity } \\
\text { (MW) }\end{array}$ & $\begin{array}{c}\text { Percentage of } \\
\text { Total Capacity }\end{array}$ & $\begin{array}{c}\text { Number of } \\
\text { Units }\end{array}$ & $\begin{array}{c}\text { Average Capacity } \\
\text { Per Unit (MW) }\end{array}$ & $\begin{array}{c}\text { Temperature } \\
\text { Range }\left({ }^{\circ} \mathbf{C}\right)\end{array}$ \\
\hline Sewage water & 891 & $56 \%$ & 54 & 17 & $10-20$ \\
Ambient water & 390 & $24 \%$ & 34 & 11 & $2-15$ \\
Industrial waste heat & 129 & $8 \%$ & 28 & 5 & $12-46$ \\
Geothermal heat & 97 & $4 \%$ & 19 & 5 & $9-55$ \\
Flue gas & 40 & $2 \%$ & 7 & 6 & $34-60$ \\
District cooling & 30 & $<2 \%$ & 4 & 7 & $0-9$ \\
Solar heat storage & 4 & $<1 \%$ & 3 & 1 & $10-35$ \\
Total & 1580 & & 149 & & $0-60$ \\
\hline
\end{tabular}

\subsection{Refrigerants}

Information about the refrigerants is available for 140 units out of the total 149, and these are separated in two categories: natural and synthetic refrigerants. The natural refrigerants are $\mathrm{NH}_{3}$ (ammonia) and $\mathrm{CO}_{2}$, whilst the synthetic refrigerants are hydrofluorocarbons (HFCs) further explained below. By building on the findings for the establishment years of the heat pumps (Table 1), Figure 2 uses the year 2006 as a border year between the new and older generations of heat pumps, to define the trends in refrigerant use.

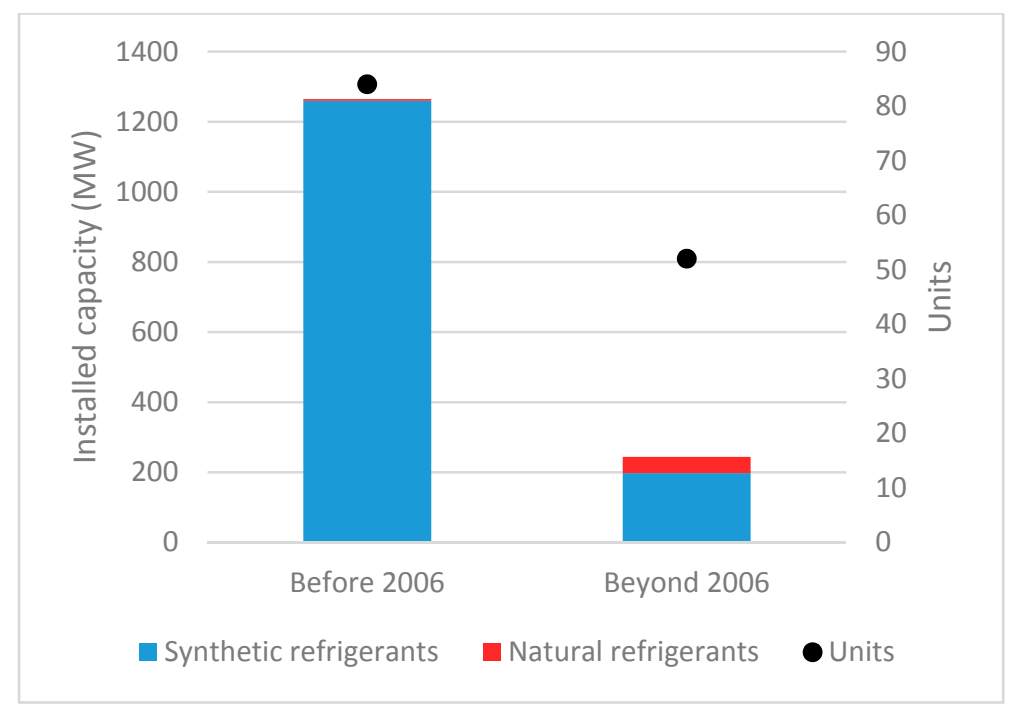

Figure 2. Breakdown of the refrigerants used by the heat pumps in the survey.

These natural refrigerants are both characterized by very low global warming potential (GWP) and non-existent ODP, which makes them available to be used with few or no environmental restrictions. They have mainly been used after 2006 and comprise 19\% of the total stock of heat pumps in this survey:

1. Ammonia $\left(\mathrm{NH}_{3}\right)$-Ammonia is a refrigerant generally used in medium and large-scale applications. It can work to temperatures up to $90{ }^{\circ} \mathrm{C}$, such as at the Drammen heat pump plant (Norway), with a COP over 3. Its efficiency is comparable with the one of the synthetic refrigerants analysed in this survey, and it is moderately flammable and toxic, so it requires specific safety precautions [25]. Due to its corrosive properties and different working temperature 
and pressure, ammonia cannot be used to retrofit the heat pumps using synthetic refrigerants, such as R-22 and R-134a. The heat pumps using $\mathrm{NH}_{3}$ account for 26 units with a total heating capacity of $51 \mathrm{MW}$, with the oldest units in the survey operating in Laussane (Switzerland) since 1986.

2. Carbon dioxide $\left(\mathrm{CO}_{2}\right)$ - Carbon dioxide is a non-toxic, non-flammable and non-corrosive refrigerant, which is generally obtained as a waste product, making it as one of the low-cost refrigerants [25]. It is also a transcritical fluid, meaning that temperature and pressure can be controlled individually, unlike other condensing (subcritical) refrigerants. It's heating COP is $25-150 \%$ better than R-134a, and is suitable for high temperature lifts, as the lower the temperature in the inlet is, the better overall efficiency it has [26]. A drawback of this refrigerant is the high pressures it must work under, making it less suitable for large-scale applications (larger than 1-2 MW). There is only one example of a large-scale heat pump using $\mathrm{CO}_{2}$ refrigerant in the survey, in the Marstal DH network in Denmark, with a heating capacity of 1.5 MW.

On the other hand, the synthetic refrigerants dominate the survey, and R-134a, present in more than $90 \%$ of the installed capacity, is the most common type of refrigerant used by the large-scale heat pumps in the survey. Another three units use R-152a and R-245fa. All these synthetic refrigerants were included on the list of controlled substances to be phased down through the Montreal Protocol by 2040 [27], and are further discussed in Section 4.2. The following section explains some of the main characteristics of these refrigerants:

1. R-134a-It is the most used HFC in the survey, and serves as refrigerant for 110 heat pumps in the survey, with a capacity over $1450 \mathrm{MW}$. It has zero ODP as it does not contain the chlorine atom, and good heat transfer properties by providing a wide temperature gap. It is also non-flammable, non-toxic and it was regarded as the most suitable option for retrofitting old heat pumps using R-12 and R-22 [28]. The refrigerant has a GWP potential of 1300, which has caused it to be prohibited already in countries such as Denmark and Switzerland.

2. R-152a-It is a HFC which has a GWP of 124 and similar thermodynamic properties as R134a, even yielding a higher COP. Generally, this refrigerant is used in blends with other refrigerants due to its very high flammability, and in the survey two heat pumps use it [29].

3. R-245fa-A HFC, generally used in high temperature applications. It has a GWP of 950 and a moderate toxicity with a critical temperature of approximately $150{ }^{\circ} \mathrm{C}$, but it works at a pressure similar to R134a [30]. In the survey, it is found in one example.

\subsection{Coefficient of Performance}

The COP represents the efficiency of a heat pump, and is given by the ratio between the thermal output and electricity input. For the heat pumps in the survey, the COP has a value between 3 and 4 and this represents the average practical COP, generally achieved throughout one year and not as a seasonal mean value over an operational phase. Also, the COP values presented in this survey do not include the electricity used by the auxiliary pumps (to pump the heat source).

Two heat pumps in Sweden, which increase the return temperature of water in the DH system by several degrees and use the R-134a refrigerant, achieved the highest COP in the survey, at 6.5. A heat pump in Denmark uses $\mathrm{NH}_{3}$ refrigerant and boosts the temperature from the inlet of the heat pump by approximately $30^{\circ} \mathrm{C}$, achieving the other high COP of 6.3. Two geothermal heat pumps in Milano give the lowest COP of 2.65, with a temperature difference between the inlet and outlet of the heat pump of $75^{\circ} \mathrm{C}$. An overview of the COP for the heat pumps in the survey is available in Figure 3, overlaid with the operating temperatures and establishment years. As a general rule, the smaller the temperature increase is, the higher the COP. 


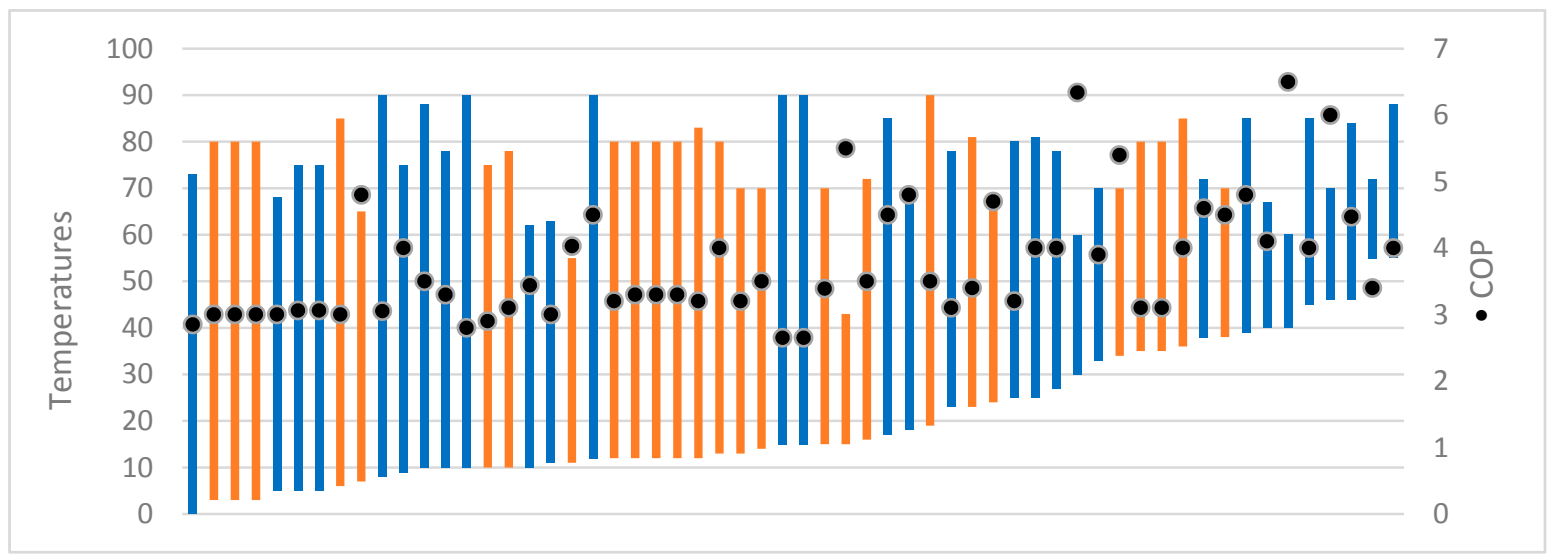

Figure 3. Operating temperatures for the heat pumps built before 2006 (orange) and beyond 2006 (blue), for the units where all the data was available (input and output temperature, coefficient of performance (COP) and establishment year). Each bar represents one heat pump.

There are many examples of heat pumps in the survey that provide a high temperature increase and a high COP, but there is no clear difference in terms of efficiency between the old and new generation of heat pumps, showing that high efficiencies were achieved by the old heat pumps even in the 1980s.

\subsection{Output Temperatures}

The temperatures the heat pumps need to operate at are defined by the requirements of each DH network, and this was considered as a barrier for the expansion of technology. However, the data gathered in the survey shows that high temperature increases have been achieved since the 1980s, and as in the case of the COP, no clear difference is found between the heat pumps built until 2005 and beyond 2006 (Figure 3). Based on the findings of the survey, the output temperatures at the condenser are classified in Table 3 and as follows:

1. Temperature $<70{ }^{\circ} \mathrm{C}$-achieved in the advanced low temperature $\mathrm{DH}$ networks using $\mathrm{NH}_{3}$ and R-134a refrigerants and generally built after the year 2006, when the need for such type of DH temperatures increased. Currently, 19 units or approximately $40 \mathrm{MW}$ of the installed capacity provides these temperature levels. The average COP of these heat pumps is 4.5. Good practice examples are found in Trondheim (Norway), Randers (Denmark) or Dietikon (Zürich).

2. Temperature between 70 and $80{ }^{\circ} \mathrm{C}$ - the most common range of temperatures found among the heat pumps in the survey, representing the delivery temperature for 57 units or over $700 \mathrm{MW}$ of the existing capacity in all the countries. These temperatures were achieved in the 1980 s by the heat pumps in Sweden.

3. Temperature $>80^{\circ} \mathrm{C}$-represented by some of the most optimised heat pumps, such as the ones in Drammen (Norway), Milan (Italy), Helsinki or Mäntsälä (Finland) and which generally have a high temperature increase. No less than half of these heat pumps were built in Sweden in the 1980s, when high temperature increases were already possible, and the survey accounts for 34 units or over $400 \mathrm{MW}$ of the installed capacity.

Table 3. Output temperature ranges with number of units, total capacity and average COP.

\begin{tabular}{cccc}
\hline Output Temperature Ranges $\left({ }^{\circ} \mathbf{C}\right)$ & $<\mathbf{7 0}$ & $\mathbf{7 1 - 8 0}$ & $>\mathbf{8 0}$ \\
\hline Units & 19 & 57 & 34 \\
Capacity (MW) & 40 & 725 & 425 \\
Average COP & 4.5 & 3.6 & 3.7 \\
\hline
\end{tabular}




\subsection{Type of Operation}

The type of operation refers to primary or the secondary load a heat pump can supply in the DH network, reflected in the operating hours, and the capacity of supplying cooling.

For the heat pumps in the survey, minimal data was provided on the operating hours and the share of production in $\mathrm{DH}$, thus their role in the DH networks could not be clearly established, as this is a parameter which fluctuates from year to year. Some of the heat pumps installed in the newest age group (2011-2016) are operated on a continuous basis (7000-8000 h/year), mainly to achieve a faster return rate of the investment, but since this data is limited, it cannot be assumed that all the heat pumps in this age group operate in the same way. These heat pumps supply the primary load, as they function continuously throughout the year and ensure a certain percentage of the base load.

Other heat pumps function on a secondary basis, with only a few operating hours, in the range of 4000-7000 h/year, operating mainly in the heating season, and very few of them function on an intermittent basis given by the price of electricity. The heat pumps in Sweden, which represent the largest share of capacity in the survey, have a capacity factor of $44 \%$, corresponding to approximately $4000 \mathrm{~h} /$ year for the period 2002-2013 [23].

Thus, it can be estimated that on average, the heat pumps in the survey have a heat output between 6.5 and $9.5 \mathrm{TWh} /$ year, considering that the operating hours can vary depending on the location, between 4000 and $7000 \mathrm{~h} /$ year, with a capacity factor between 45 and $70 \%$.

According to [23], the experiences from Swedish heat pumps demonstrate that the number of start-ups are within the limit of normal operation of the electrical compressors which are considered to be among the most vulnerable components of a heat pump. This statement relates to the operation of the heat pumps in Gothenburg, which have operated since the 1990s only in connection with the price of electricity [31]. However, this is challenged in [8], where it is stated that heat pumps are profitable in continuous operation along with a stable electricity supply, and where frequent start-ups create mechanical wear along with a low COP during the start-ups.

Therefore, the existing knowledge on the lifetime of the components for large-scale electric heat pumps is limited, but according to [32], the first components to suffer from mechanical wear are the components of the compressor, such as impellers, bearings or shaft seals. Other parts, like the electrical engine, gears, coupling, tubes in heat exchangers and computer systems are also known to require replacement especially when the unit reaches 20-30 years of operation. Finally, it is important to note that the existing large-scale heat pumps have not been designed so far for flexible regulation to include numerous starts-ups.

\section{District Cooling}

Besides their heating needs, some buildings have cooling requirements too. Many of the existing district cooling networks are in the Nordic countries, where district cooling received a growing interest, due to an increased concentration of local businesses, environmental friendliness, energy efficiency and opportunity of improving the profitability of a plant. These cooling networks are smaller than the heating ones, and usually supply the service and industry sectors. The cold water is distributed to the customers in similar ways as the hot water for $\mathrm{DH}$. The technology is generally constituted by absorption or mechanical chillers, but also by natural cooling, using the water from the cold lakes or streams. The electric large-scale heat pumps have the capacity to provide both the heating and cooling needs, and the survey accounts for 49 units that supply cold water in district cooling networks, besides the heating needs.

\section{Possible Deployment and Potential in Europe}

There are multiple factors considered for a quantitative expansion of large-scale heat pumps in more DH systems in Europe. A first observation in the trend across all three generations of DH was a decrease of the distribution temperature [33], an outcome proving beneficial for the use of heat pumps, 
which provide better COP when the temperature lift is lower. The necessary output temperatures of heat pumps are given though by the refrigerant used, temperature of the heat source, along with other characteristics, such as the compressor or contact surface of the heat exchangers [34].

Four aspects can prove defining for a possible future deployment of this technology, and are analysed in this section, structured on the findings of the survey. These relate to heat sources, refrigerants, output temperatures and type of operation.

\subsection{Heat Sources}

The heat pumps in the survey use various types of heat sources in the form of sewage and ambient water, industrial waste heat, geothermal heat, flue gas, district cooling and solar heat storage. DH provides the ability to use this heat locally, as otherwise this energy would be lost. Much of this energy is currently lost, as there is more waste heat in Europe than the necessary to supply the entire heat demand [7]. In the scenario where all this heat could be effectively captured, it would only need to be transported through DH to the consumers. Nevertheless, not all of the heat has the required temperature levels, so solutions in the form of large-scale heat pumps enable the effective use of this heat. By analysing the type of heat sources presented in Section 3.2, there are several observations to make about the types of heat sources used.

A first observation relates to the range of heat source temperatures, which starts from $0{ }^{\circ} \mathrm{C}$ and goes up to $60{ }^{\circ} \mathrm{C}$, and in all the cases these temperatures prove compatible for upgrading to the required DH temperatures (which differ in each country and network). The temperatures that go above the highest temperature presented here should be suitable for direct use in a low-temperature DH system.

A second observation relates to the type of heat source used. Sewage water is the most common type of heat source used by the heat pumps in the survey, with 913 MW of installed capacity, representing $57 \%$ of all the total capacity reviewed in this survey. This type of heat source is regarded as a long-term stable type of heat source [23] and the largest capacities of heat pumps using it are installed in cities such as Stockholm (230 MW), Gothenburg (160 MW), Helsinki (90 MW), or Oslo (40 MW). Since these cities managed to make use of this heat source, similar solutions could be applied in other major European cities that benefit or will benefit from DH systems too.

The same can be stated about ambient water, which can be a valuable heat source despite its generally lower temperatures. Accessible in coastal areas or in the proximity of large rivers or lakes, it can provide a stable and secure source of heat throughout the year. For more than 30 years the largest sea water heat pumps in the world ( $250 \mathrm{MW}$ ) have been operating in Stockholm and even though the sea water temperatures have an average of $3{ }^{\circ} \mathrm{C}$, the heat pumps can raise the temperature to $80^{\circ} \mathrm{C}$, whilst achieving a COP of 3 . The ammonia-based heat pumps in Drammen (Norway) achieve similar results. Ambient water provides the ability to provide a high debit of water, thus enabling the heat pumps to extract more heat.

A third observation relates to the use of industrial waste heat, and the HRE studies identified that there are vast amounts of excess heat currently being wasted in Europe. According to the survey, at least 28 heat pumps use this type of heat in Europe today. Therefore, from a heat recovery and distribution perspective, large-scale heat pumps and $\mathrm{DH}$ systems can prove a viable solution for many locations in Europe. By correlating the excess heat sources with the heating demands, it results that these are often located in the proximity of urban areas [7,35]. Some of the excess heat resources indicated in this study include low temperatures too, coming from industries such as chemical, food, beverage, paper or printing, producing excess heat that can be captured by heat pumps. Examples of such heat pumps in DH systems using these types of excess heat are the Skjern paper mill (Denmark), Wörgl diary factory (Austria), or the network in Rheinfelden 2 (Switzerland), which uses the waste heat from the brewing factory. However, thermal power generation have the highest levels of excess heat, with approximately $70 \%$ of heat originating from power plants, which can be used directly in the DH systems [36]. In addition, it is important to note that this type of heat source is dependent on 
the industry supplying it, and in Sweden the heat pumps using industrial waste heat represented the highest number of decommissioned units between 2000 and 2013 [23].

Thus, given the types of heat sources in use today by the heat pumps reviewed in this survey, and their relative equal spread in the proximity of urban areas, it can be concluded that from a heat source perspective that the possibilities of using these sources are varied. Sewage water has the greatest advantages, due to its relatively high temperature, long-term stability and proximity to urban areas. Industrial waste heat shares the same advantages as the sewage water, but lacks long-term stability. Finally, even the low temperature heat sources, such as ambient water and the return of district cooling, can be successful heat sources, whilst also reaching an average COP of 3. Sewage, ambient and geothermal water and waste heat remain as the most common heat sources, but after the year 2000 new types of heat sources emerged, such as flue gas and solar heat storage, which may prove to have a more important role in the future $\mathrm{DH}$ systems. These characteristics are summarized in Table 4.

Table 4. Characteristics of the heat sources used by the heat pumps in the survey $(\Delta$ high, - medium, $\nabla$ low).

\begin{tabular}{cccc}
\hline Type of Heat Source & Temperature & Stability/Security & Proximity to Urban Areas \\
\hline Sewage water & - & - & \\
Ambient water & - & - & - \\
Industrial waste heat & $\mathbf{A}$ & - \\
Geothermal water & $\mathbf{V}$ & $\mathbf{-}$ & - \\
Flue gas & $\mathbf{A}$ & & \\
District cooling & Solar heat storage &
\end{tabular}

\subsection{Refrigerants}

The refrigerants used today by the electric large-scale heat pumps have a good applicability and compatibility with the existing compressor heat pumps, but HFC refrigerants have already encountered legislation issues in countries such as Denmark or Switzerland. In Denmark the use of $\mathrm{R}-134 \mathrm{a}$ is quantities larger than $10 \mathrm{~kg}$ has been prohibited since 2006 [37] whilst Switzerland adopted a similar strategy, with a strengthened national F-gas policy, which prohibits the placement on the market of stationary units using HFC, specifically units with capacities over $600 \mathrm{~kW}$ starting from December 2013 [38].

On an EU policy level, there is currently no restriction on the use of HFCs for large-scale applications in the heating and cooling sector, but restrictions were issued for refrigerants with high levels of GWP in the latest F-gas regulations [39]. A tendency of migration from synthetic to natural refrigerants can be observed along with newly-developed projects. This is related to the improved physical properties of the natural refrigerants (especially of $\mathrm{NH}_{3}$, where the technology has reached a certain maturity) but is also due to the push for changes on a policy level, which aim to reduce the use of powerful greenhouse gases. One such recent change is the amendment to the Montreal Protocol, signed in October 2016 at the 28th Meeting of Parties, which adds the HFCs to the list of controlled substances to be phased down by 2040. The amendment will enter into force starting with the 19th of January 2019, provided that at least 20 parties ratify it. Otherwise, it will enter force 90 days after the ratification by the 20th party. This applies to developed countries, thus the EU. The phase-down will be done in steps, so that by 2040 the levels of HFCs will be reduced by $85 \%$ compared to the average consumption in 2011-2013 plus 15\% of HCFCs (hydrochlorofluorocarbons) as the baseline [27]. The amendment might bring barriers to the inclusion of more large-scale heat pumps in the future DH systems, but options do exist. The safest options to go with in the future are the natural refrigerants, such as $\mathrm{NH}_{3}$ and $\mathrm{CO}_{2}$, whilst some heat pump manufacturers are considering 
the use of a new family of refrigerants, namely hydrofluoroolefins (HFOs). Each of these refrigerants has its advantages and disadvantages.

The new generations of heat pumps using $\mathrm{NH}_{3}$ have reached a certain level of technological maturity and can achieve similar performances or outrun the heat pumps using HFCs. A possible drawback is the capacity such heat pumps can achieve, which is currently not more than $6 \mathrm{MW}$ thermal output per unit, but this can always be overcome by connecting multiple modules together if the space for them exists. Another possibly viable refrigerant for the future is $\mathrm{CO}_{2}$, which can provide high performances, but the high pressures this refrigerant needs to work at establish the main barrier in the development of larger capacities for this type of heat pump. This mainly affects the bigger parts of the assemblies and the internal piping. The larger the subassembly, the higher the pressure, and more compressors are necessary to achieve $1 \mathrm{MW}$ thermal output than for an equivalent $\mathrm{NH}_{3}$ heat pump. Overall, the development of this technology in relation to $\mathrm{DH}$ could prove beneficial, as $\mathrm{CO}_{2}$ heat pumps usually have low return temperatures due to low temperatures in the evaporation process, which leads to higher efficiencies [24].

The third option are the HFOs, with the R-1234yf and R-1234ze refrigerants intended for usage with large-scale heat pumps. The literature concerning these refrigerants is very limited, and most of this information was obtained through personal communication [24,40-42]. Known as the fourth generation of refrigerants, the HFOs are similar to HFCs, as they contain hydrogen, fluorine and carbon, but unlike the HFCs they have a GWP of 4 . No heat pumps in the survey use this type of refrigerant, but new projects currently in development will use it. These refrigerants are a possible replacement for the HFCs due to their similar thermodynamic properties that allow the replication of large-scale heat pump such as the ones built in Sweden in the 1980s, but generally have a reduced efficiency compared to the HFCs. However, these refrigerants are contested in some circles because of the toxic substances they release in case of leaks and after their breakdown in the atmosphere. Another disadvantage is their flammability, but this is a characteristic shared with ammonia. Overall, the future of the HFOs is uncertain, and even though they are already prohibited in countries as Denmark, (put the same category as the HFCs), exceptions to this rule were granted, due to their low GWP. On a European level, there are currently no regulations acting against the use of these refrigerants, nor they are mentioned as part of the prohibited substances in new amendment adopted to the Montreal Protocol, but their future is uncertain, due to their toxicity and lack of knowledge on long-term behaviour.

Therefore, given the concern for reducing the GHG emissions, the learning curve, accumulated knowledge and the regulatory support, $\mathrm{NH}_{3}$ presents itself as the safest refrigerant for the expansion of electric large-scale heat pumps in the future with the current knowledge, leaving the $\mathrm{CO}_{2}$ as a second solution for smaller capacities (up to $2 \mathrm{MW}$ ). The HFOs are also regarded as an option for a future expansion, but the characteristics of this new family of refrigerants could bring them in the same situation as the HFCs used today. Of note, besides the above presented categories, other substances such as hydrocarbons or water can be used refrigerants, but the technology remains in the demonstration phase for the use in DH systems.

\subsection{Operating Temperatures}

In the past large-scale heat pumps were generally avoided as they were not considered as capable for supplying high enough temperatures for the DH. This was related to their technological design, being derived from chillers, as the refrigerant used with the electric motor could only allow temperatures of maximum $65^{\circ} \mathrm{C}$ [34]. However, this can be partly addressed by the technology used in the 1980s in Sweden, where many large-scale heat pumps could already supply temperatures over $70{ }^{\circ} \mathrm{C}$, reaching up to $90^{\circ} \mathrm{C}$ while still achieving a COP over 3 .

Nowadays, the old heat pumps in Sweden still function and deliver the required output temperatures, and are followed by new generations of heat pumps that can deliver temperatures of $80^{\circ} \mathrm{C}$, or even $90^{\circ} \mathrm{C}$, using natural refrigerants. These may prove reliable as heat suppliers for the $\mathrm{DH}$ networks. Since it is necessary for the future generations of $\mathrm{DH}$ to decrease their distribution 
temperatures [12], this can only provide advantages for heat pumps, as the decrease in temperatures will allow an increase in efficiency. As presented in Table 3, there is a strong correlation between low-temperature $\mathrm{DH}$ systems and high COPs, as in the range of heat pumps supplying temperatures below $70{ }^{\circ} \mathrm{C}$, the average $\mathrm{COP}$ is 4.6 , compared to the rest of the heat pumps, where the COP between 3.5 and 4 .

\subsection{Type of Operation}

Most the heat pumps in the survey supply a secondary load of the total heat demand in their DH networks. The capacity factor of the heat pumps in Sweden reduced in the period 2002-2013 and it is likely to still be reduced because to the increased competition of biomass and waste CHP, but also because of higher electricity prices. In the scenario of a highly electrified energy system and increased DH levels on a European level, the role of these power-to-heat systems will become more important.

Electric large-scale heat pumps are documented as critical components of a Smart Energy System [9], and the combination between CHP and heat pumps and can provide the advantages of both the flexibility of fuels (such as biomass and waste) and the low prices of intermittent electricity. From a technical point of view, heat pumps can also be integrated along with CHP units, provided that the necessary DH temperatures are below $90^{\circ} \mathrm{C}$ [34].

One of the first steps in this integration process is the connection between the thermal and electricity sectors. Since most of the electricity demand is already produced by CHP, the integration is in place to some extent. In combination with cogeneration plants and other sources, the heat pumps can utilise inexpensive thermal storage systems in the DH network compared to other integration and energy storage options. These can typically store $2-8 \mathrm{~h}$ of heat demand in the DH [13,43].

By integrating this type of operation, the CHP plant can be operated in such a way to benefit from the integration with RES. That is, when the RES production is high, the CHP is used less and the heat pump has priority. When the RES production decreases, the CHP is used more with reduced priority for the heat pump (Figure 4). The advantage of such a system with added thermal storage capacity is that it can integrate fluctuating RES to a high percentage without losing the overall efficiency $[44,45]$.
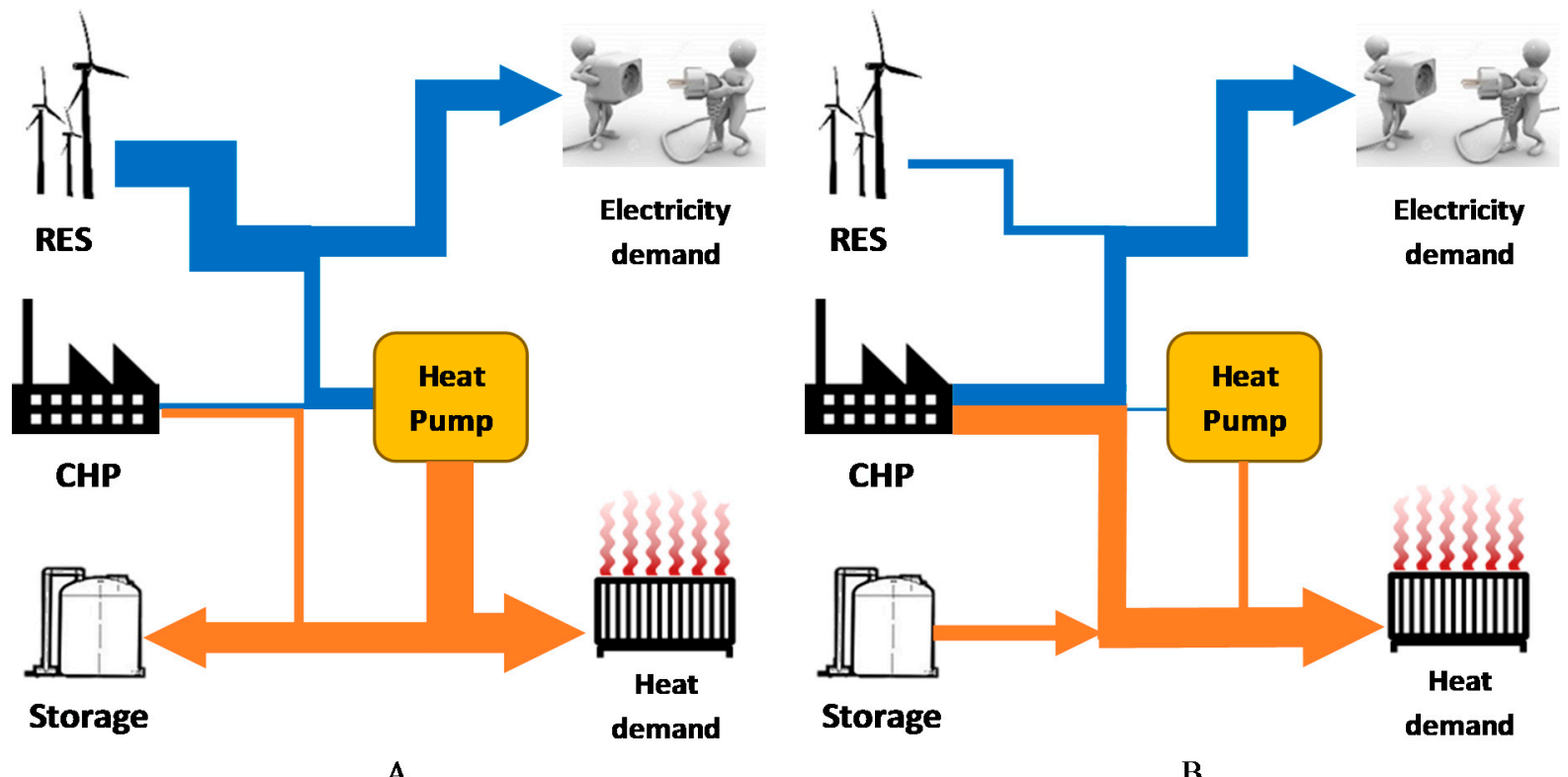

A

B

Figure 4. Higher renewable energy sources (RES) production, lower combined heat and power (CHP) use (A) and lower RES production, higher CHP use (B). 
The same functioning principle can be applied when the electricity price decreases and / or the fuel price increases, triggering more heat pump use, and vice-versa, when the electricity price increases and/or the fuel price decreases, allowing the CHP to be used more. Another advantage of this type of integration can be related to the outdoor temperatures, by using the CHP in times of very low outdoor temperatures and more heat pump when the temperatures are higher.

The future partnerships between CHP and large-scale heat pumps can also include 'cold storage', where the flue gases are stored and recovered later by the heat pump, which can operate even when the CHP is not functional. This type of operation opens the opportunity for a high degree of flexibility in the plant operation, allowing for efficient and flexible use of electricity for heat production, and allows the operation of the heat pump with no additional temperature lift towards heat storage. In the CHP - heat pump - cold storage combination, low temperature heat from flue gases is recovered and stored during the operation hours of the CHP. The stored heat in the 'cold storage' is used as a heat source for the heat pump, operational at high COP, due to the high temperature of the heat source. The heat pump can function even when the CHP is not operational and this mode can be used when the electricity prices are low due to a high proportion of intermittent electricity. The main advantage of this type of operation is its capability to provide the required temperature for the $\mathrm{DH}$, which usually is above $80^{\circ} \mathrm{C}$ [15]. While in [15] a transcritical heat pump was considered for this partnership, other subcritical heat pumps can also be used.

Therefore, heat pumps are maximising the efficiencies of the heating plants by using their own waste heat, but have not been used so far to balance intermittent electricity sources on a large scale, only to integrate a constant surplus of electricity, like the one produced by the nuclear power plants in Sweden in the 1980s.

Exceptions to this rule exist, as the largest existing heat pumps in Gothenburg have been used solely on a start/stop basis, dependent on the price of electricity [31]. If this is already achieved to some extent with old technology, there is no reason this cannot be done with newer technology. Thus, it finally becomes a deliberation of risk management. If electricity prices are a constant low, then it is not an issue, as the heat pumps can operate as much as possible, but then it is also difficult to compete economically for balancing purposes. If the mechanical wear can be ruled out for frequent start-ups with the new generations of heat pumps, or if the operation and management costs are low enough to encourage frequent start-ups, then the large variation of electricity prices becomes more practical, as more intermittent power generation is added to the electrical grid.

Again, it is important to note that so far heat pumps have not been designed for flexible regulation. This should be a focus point in the future development.

\section{District Cooling}

As part of the operation of heat pumps, cooling can also provide operational gains. As mentioned before, the main advantage of such a network is the economic gains it can achieve, represented by the shared costs of installing and operating the system, as not everybody can afford to install and operate an individual cooling system. The space made vacant by the replacement of individual cooling units with district cooling can be an advantage, as well as the reduction in noise from the cooling machines. In some cases, individual air-conditioning systems can put additional stress on the local electricity grids, so a cooling grid with water temperatures just over freezing can represent a solution. However, one issue with this system is with respect to the return temperatures of the grid, which are often below $10{ }^{\circ} \mathrm{C}$, so the piping must be larger for the same effect transport. Consequently, this could make a district cooling network more expensive than a DH network for the same piping length [46].

Currently, the district cooling covers approximately $1 \%$ of the cooling demands, whilst the majority is ensured by individual heat pumps/chillers [7]. The cooling sector itself represents only a small fraction of the heating and cooling sector, leaving a great amount of choice for the future development of the cooling supplies. According to the HRE studies, the choice of cooling supplies is likely to have minor influences on the national energy supplies if the demands remain the same, but 
could have higher impact on a local level [7]. One third of the heat pumps in the survey also supply district cooling, due to the availability for such demand and its economic advantages. The future deployment of large-scale heat pumps should not be defined by the necessity for supplying both the heating and cooling demands, but by local strategies. Thus, the national strategies should focus more on integrating the intermittent RES with the thermal sector, as the heating demands are higher than the cooling demands, even in the countries in Southern Europe [7].

\section{Conclusions and Policy Implications}

The available data was sufficient to create an overview over the status of this technology in Europe, and analyse its most relevant patterns. The lack of cooperation and interest of some stakeholders to share more data affected the completion of this survey. More data would have made the results of the survey more precise, but overall, it would not have changed the understanding of the technology used nowadays by the electric large-scale heat pumps.

Summarising the identified types of heat sources used by the heat pumps in the survey indicates that there is a huge potential for using sewage water and ambient water as the main heat sources for the future heat pumps due to their long-term stability, proximity to urban areas and not least of all, temperatures, mainly for sewage water. These types of heat sources are considered as the main enablers for achieving the capacities estimated in HRE, of $40 \mathrm{GW}$ thermal output. Industrial waste heat is also an important heat source, despite its higher risk of providing long-term stability, as there is a high potential for using it either directly, or enabled by a heat pump, since the temperatures are generally high. The other heat sources are worth mentioning too, as solar heat storage, geo-thermal energy or flue gas represent valuable resources that good can be quantitatively expanded to other locations in Europe.

DH temperatures are generally achieved without compromises in terms of COP, and the present generation of heat pumps can supply the necessary temperatures of the DH systems by using natural refrigerants. However, since heat pumps are more efficient when providing lower temperatures, consideration should be given to low temperature networks, which have reduced losses in the grids and provide low temperature return, of critical importance for the future DH networks.

Regarding their type of operation, in a future scenario with more renewables in the energy system produced by wind and solar sources, the large-scale heat pumps can bring more advantages by functioning on an intermittent basis. The integration of large-scale heat pumps in DH systems adds resilience to the electric and thermal grids by taking advantage of the low-cost electricity prices on the spot market, and by using electricity to generate heat. Such an integration can help reduce the surplus electricity on a grid and help to shave the peak electricity production if enough capacity is installed. Since an electricity surplus once led to the expansion of large-scale heat pumps in DH systems in Sweden in the 1980s, it is possible that the situation could repeat once again with the increasing amounts of electricity from wind and solar.

Thus, the technological limitations do not seem to be a barrier, but there are policy limitations that do not give heat pumps an advantage compared to other technologies, even though from a socio-economic perspective, they are critical elements of the future energy system. Specifically, an energy market with no carbon penalty, biomass and fossil fuel subsidies is not helpful for the expansion of this technology. For example, biomass is a limited resource, but has more financial incentives than using heat pumps. Even though DH is generally well promoted by policy makers, the connection with heat pumps is rarely made due to a lack of knowledge or willingness to remain technology-neutral. Since heat pumps do not benefit of tax exemptions or subsidies like other technologies do, these end up with a higher investment cost than their competitors. One could also raise the question of more moderate DH expansion than that suggested in the HRE studies, as well as a lack of abundant heat sources, which would decrease the role of large-scale heat pumps in the future. However, as demonstrated in this study, the potential exists. 
To conclude, the technology used nowadays by the electric large-scale heat pumps has reached a satisfying level of maturity to be further deployed in existing and future DH systems across Europe if careful consideration is put in choosing the right refrigerant to comply with environmental requirements, and if the technological design is aimed at frequent start-ups to be able to integrate intermittent renewable electricity sources.

Supplementary Materials: The following are available online at www.mdpi.com/1996-1073/10/4/578/s1.

Acknowledgments: The work presented in this paper is a result of the research activities of the $4 \mathrm{DH}$ Research Centre, financed by The Innovation Fund Denmark (0603-00498B) and Heat Roadmap Europe 2050, financed by the European Union's Horizon 2020 research and innovation program (grant agreement 695989). Valuable input has been received from Heat Roadmap Europe 2050 colleagues, researchers and partners. The authors would also like to thank Paul Ingvarsson for valuable contributions throughout the development of this study.

Author Contributions: Andrei David collected data in the survey and wrote the paper; Brian Vad Mathiesen conceived the study and provided HRE knowledge; Helge Averfalk collected the data from Sweden; Sven Werner analyzed the data and structured it; Henrik Lund designed and wrapped up the study.

Conflicts of Interest: The authors declare no conflict of interest.

\section{References}

1. United Nations Framework Convention on Climate Change (UNFCCC). The Paris Agreement. 2016. Available online: http:/ / unfccc.int/paris_agreement/items/9485.php (accessed on 18 January 2017).

2. European Commission. Energy Roadmap 2050, COM(2011) 885 Final; European Commission: Brussels, Belgium, 2011.

3. Eurostat. Greenhouse Gas Emission Statistics. Eurostat Statistics Explained. 2015. Available online: http:/ /ec.europa.eu/eurostat/statistics-explained/index.php/Greenhouse_gas_emission_statistics (accessed on 10 August 2016).

4. European Commission. European Energy Security Strategy; European Commission: Brussels, Belgium, 2014; p. 24.

5. European Commission. An EU Strategy on Heating and Cooling, COM(2016) 51 Final; European Commission: Brussels, Belgium, 2016.

6. Connolly, D.; Mathiesen, B.V.; Østergaard, P.A.; Möller, B.; Nielsen, S.; Lund, H.; Trier, D.; Persson, U.; Nilsson, D.; Werner, S. Heat Roadmap Europe: First Pre-Study for EU27; Aalborg University: Aalborg, Denmark, 2012.

7. Connolly, D.; Mathiesen, B.V.; Østergaard, P.A.; Möller, B.; Nielsen, S.; Lund, H.; Persson, U.; Werner, S.; Grözinger, J.; Boermans, T.; et al. Heat Roadmap Europe: Second Pre-Study; Aalborg University: Aalborg, Denmark, 2013.

8. Averfalk, H.; Ingvarsson, P.; Persson, U.; Werner, S. On the use of surplus electricity in district heating systems. In Proceedings of the 14th International Symposium on District Heating and Cooling, Stockholm, Sweden, 6-10 September 2014; pp. 7-12.

9. Mathiesen, B.V.; Lund, H.; Connolly, D.; Wenzel, H.; Ostergaard, P.A.; Möller, B.; Nielsen, S.; Ridjan, I.; Karnøe, P.; Sperling, K.; et al. Smart Energy Systems for coherent 100\% renewable energy and transport solutions. Appl. Energy 2015, 145, 139-154. [CrossRef]

10. Lund, H.; Hvelplund, F.; Mathiesen, B.V.; Østergaard, P.A.; Christensen, P.; Connolly, D.; Schaltz, E.; Pillay, J.R.; Nielsen, M.P.; Felby, C.; et al. Coherent Energy and Environmental System Analysis; Aalborg University: Aalborg, Danmark, 2011.

11. Blarke, M.B.; Lund, H. The effectiveness of storage and relocation options in renewable energy systems. Renew. Energy 2008, 33, 1499-1507. [CrossRef]

12. Lund, H.; Werner, S.; Wiltshire, R.; Svendsen, S.; Thorsen, J.E.; Hvelplund, F.; Mathiesen, B.V. 4th Generation District Heating (4GDH): Integrating smart thermal grids into future sustainable energy systems. Energy 2014, 68, 1-11. [CrossRef]

13. Mathiesen, B.V.; Lund, H. Comparative analyses of seven technologies to facilitate the integration of fluctuating renewable energy sources. IET Renew. Power Gener. 2009, 3, 190-204. [CrossRef] 
14. Mathiesen, B.V.; Blarke, M.B.; Hansen, K.; Connolly, D. The Role of Large-Scale Heat Pumps for Short Term Integration of Renewable Energy; Department of Development and Planning, Aalborg University: Aalborg, Danmark, 2011.

15. Blarke, M.B.; Lund, H. Large-scale heat pumps in sustainable energy systems: System and project perspectives. Therm. Sci. 2007, 11, 143-152. [CrossRef]

16. Blarke, M.B.; Dotzauer, E. Intermittency-friendly and high-efficiency cogeneration: Operational optimisation of cogeneration with compression heat pump, flue gas heat recovery, and intermediate cold storage. Energy 2011, 36, 6867-6878. [CrossRef]

17. Sievers, J.; Faulstich, S.; Puchta, M.; Stadler, I.; Schmid, J.; Madina, C.; Díaz, Á.; Ruiz, N.; Turienzo, E.; Münster, E.; et al. Long-Term Perspectives for Balancing Fluctuating Renewable Energy Sources; University of Kassel: Kassel, Germany, 2007.

18. Lund, R.; Persson, U. Mapping of potential heat sources for heat pumps for district heating in Denmark. Energy 2016, 110, 129-138. [CrossRef]

19. Mathiesen, B.V.; Lund, H.; Connolly, D. Limiting biomass consumption for heating in $100 \%$ renewable energy systems. Energy 2012, 48, 160-168. [CrossRef]

20. Bach, B.; Werling, J.; Ommen, T.; Münster, M.; Morales, J.M.; Elmegaard, B. Integration of large-scale heat pumps in the district heating systems of Greater Copenhagen. Energy 2016, 107, 321-334. [CrossRef]

21. Mathiesen, B.V.; Lund, H.; Karlsson, K. 100\% Renewable energy systems, climate mitigation and economic growth. Appl. Energy 2011, 88, 488-501. [CrossRef]

22. Lund, R.; Ilic, D.D.; Trygg, L. Socioeconomic potential for introducing large-scale heat pumps in district heating in Denmark. J. Clean. Prod. 2016, 139, 219-229. [CrossRef]

23. Averfalk, H.; Ingvarsson, P.; Persson, U.; Werner, S. Large heat pumps in Swedish district heating systems. 2017; Manuscript submitted for publication.

24. Ingvarsson, P.; AF Consult, Stockholm, Sweden. Personal Communication, 2017.

25. Riffat, S.B.; Afonso, C.F.; Oliveira, A.C.; Reay, D.A. Natural refrigerants for refrigeration and air-conditioning systems. Appl. Therm. Eng. 1997, 17, 33-42. [CrossRef]

26. Austin, B.T.; Sumathy, K. Transcritical carbon dioxide heat pump systems: A review. Renew. Sustain. Energy Rev. 2011, 15, 4013-4029. [CrossRef]

27. United Nations Environment Programme (UNEP). Amendment to the montreal protocol on substances that deplete the ozone layer. In Proceedings of the 28th Meeting of the Parties, Kigali, Rwanda, 8-14 October 2016.

28. Johansson, A. Phase-Out of Refrigerant R22. Ph.D. Dissertation, Royal Institute of Technology, Stockholm, Sweden, 2003.

29. Kilicarslan, A.; Müller, N. A comparative study of water as a refrigerant with some current refrigerants. Int. J. Energy Res. 2005, 29, 947-959. [CrossRef]

30. Zyhowski, G.J.; Spatz, M.M.; and Motta, S.Y. An Overview Of The Properties And Applications of HFC-245fa. Proceedings of the International Refrigeration and Air Conditioning Conference, Purdue university, West Lafayette, IN, USA, 16-19 July 2002.

31. Dalman, B.G.; Göteborg Energi, Gothenburg, Sweden. Personal Communication, 2015.

32. Ingvarsson, P. Handbok för livslängdsarbete med energianläggningar (Handbook for lifespan work with 719 energy plants); Värmeforsk report no. 885; Swedish DH Association: Stockholm, Sweden, 2004.

33. Frederiksen, S.; Werner, S. District Heating and Cooling; Studentlitteratu: Lund, Sweden, 2013.

34. De Jong, K. Industrial Heat Pumps and CHP as Partners; Stichting Warmtenetwerk: Hilversum, The Netherlands, 2014.

35. Persson, U.; Möller, B.; Werner, S. Heat Roadmap Europe: Identifying strategic heat synergy regions. Energy Policy 2014, 74, 663-681. [CrossRef]

36. Persson, U. Stratego. Ehanced heating and Cooling Plans. In Quantifying the Excess Heat Available for District Heating in Europe, WP2; Background Report 7; Aalborg University: Aalborg, Denmark, 2015.

37. Ministry of the Environment \& Danish Environmental Protection Agency. Statutory Order No. 552 of 2 July 2002 Regulating Certain Industrial Greenhouse Gases; No. 552; Ministry of the Environment \& Danish Environmental Protection Agency: Copenhagen, Denmark, 2002.

38. Hydrocarbons21.com. Switzerland to Introduce HFC Bans in Several AC and Refrigeration Applications. 2012. Available online: http://www.hydrocarbons21.com/articles/3659/switzerland_to_introduce_hfc_ bans_in_several_ac_and_refrigeration_applications (accessed on 5 November 2016). 
39. The European Parliament and the Council of the European Union. Regulation (EU) No 517/2014 of the European Parliament and of the Council of 16 April 2014 on fluorinated greenhouse gases and repealing Regulation (EC) No 842/2006. Off. J. Eur. Union 2014, 2014, 195-230.

40. Pachai, A.C.; Johnson Controls, Milwaukee, WI, USA. Personal Communication, 2016.

41. Vonsild, A.L.; Danfoss, Copenhagen, Denmark. Personal Communication, 2016.

42. Greenpeace. HFOs: The New Generation of F-Gases; Greenpeace: Amsterdam, The Netherlands, 2016.

43. Mathiesen, B.V. Fuel Cells and Electrolysers in Future Energy Systems. Ph.D. Dissertation, Aalborg Universitet, Aalborg, Denmark, 2008; p. 328.

44. Lund, H.; Andersen, A.N.; Østergaard, P.A.; Mathiesen, B.V.; Connolly, D. From electricity smart grids to smart energy systems-A market operation based approach and understanding. Energy 2012, 42, 96-102. [CrossRef]

45. Lund, H. Electric grid stability and the design of sustainable energy systems. Int. J. Sustain. Energy 2005, 24, 45-54. [CrossRef]

46. Söderman, J. Optimisation of structure and operation of district cooling networks in urban regions. Appl. Therm. Eng. 2007, 27, 2665-2676. [CrossRef]

(C) 2017 by the authors. Licensee MDPI, Basel, Switzerland. This article is an open access article distributed under the terms and conditions of the Creative Commons Attribution (CC BY) license (http:/ / creativecommons.org/licenses/by/4.0/). 